\title{
Ética e Investigación Científica en la Sociedad Globalizada
}

\author{
COLOMBA NORERO V. ${ }^{1}$, CARLOS TORO A. ${ }^{2}$, JAIME CONTRERAS P. ${ }^{3}$ \\ 1. Vicedecana Facultad de Medicina. Universidad Andrés Bello. \\ 2. Director de Postgrado, Facultad de Medicina. Universidad Andrés Bello. \\ 3. Director Escuela de Medicina. Universidad Andrés Bello.
}

El hombre del siglo XXI se enorgullece de pertenecer a una cultura que privilegia el conocimiento y la innovación. Sin embargo, durante su larga historia y no obstante su inteligencia, el hombre - arrastrado por su soberbia- no siempre ha sido capaz de percibir con humildad las limitaciones de sus capacidades, lo que ha causado duros golpes no sólo a su ego sino también graves detenciones y retrocesos a la especie humana.

Para Freud, las grandes conmociones que ha sufrido la humanidad han sido: - Dejar de ser la tierra el centro del Universo (Copérnico); - Dejar de ser la especie humana la coronación del mundo animado (Darwin); - Dejar de ser los hombres, amos de sus propios impulsos (psicoanálisis), a lo cual debemos agregar desde el siglo XX: Dejar de ser los hombres amos de sus técnicas ${ }^{1}$.

Estas conmociones ilustran dos aspectos de la especie humana que son contradictorios: El contraste entre su inteligencia y la profundidad de sus errores conceptuales que sentaron las bases para concepciones teóricas sustentadas largo tiempo y de tal arraigo, que incluso lo impulsaron, en determinadas épocas, a dar muerte en calidad de sacrílegos, a los que visionariamente pretendieron modificar el esquema de pensamiento vigente.

Pero, ¿ha aprendido el hombre algo de humildad?

Hasta principios del siglo XX, el conocimien- to se basaba en la transmisión directa de experiencia, lo que era muy notorio en Medicina. El juicio personal sumado a experiencias ajenas semejantes, contribuía a resolver el problema que se enfrentaba con un elemento de subjetividad enorme ${ }^{2,3}$. Posteriormente, el conocimiento fue el resultado de la interpretación de los hechos observados mediante el uso del método científico. En el ambiente actual la investigación va más allá de las fronteras y le cabe abrir caminos con libertad e independencia de las aplicaciones que puedan dársele a sus descubrimientos, mientras que a la Innovación le corresponde desarrollar las potencialidades de éstos, aplicando en la práctica determinados aspectos derivados de ellos, lo que a su vez provoca la introducción de novedades adicionales. Así, es creativa en el sentido de crear necesidades.

De esta manera como consecuencia de una potenciación técnica y capacitación intelectual nunca antes logradas, la inventiva del hombre ha alcanzado niveles insospechados lo que le permite escudriñar el mundo y a la especie humana hasta sus partículas esenciales, dando rienda suelta al gozo de descubrir y entender, sin imaginar que, por desgracia, las aplicaciones que se darán en algunos casos a estos nuevos conocimientos pueden convertirse en fines en sí mismos que siguen "perfeccionándose" con independencia de sus creadores.

Así pues, la actual es una sociedad que contrasta sueños y patentes, tratando de conci-

Correspondencia a:

Dra. Colomba Norero V.

E-mail:cnorero@unab.cl 
liar sus mutuos intereses: comprensión de un problema y aplicación práctica, utilitaria, de la novedad y sus derivaciones, con la mayor rapidez y difusión posible.

... "Dejan de ser los hombres, amos de sus técnicas".

El impacto de la aplicación del conocimiento científico y tecnológico en el bienestar de la humanidad es evidente: por ejemplo, los sistemas de transporte y de comunicación, de tan incorporados, ya no se aprecian en lo que han significado para la modificación de nuestros hábitos. Esta misma situación de "aceptación por uso" sobre otros puntos nos inquietan sobremanera, por ejemplo, hasta donde puede llevar el desarrollo de la biología molecular y sus implicancias éticas a modificar los conceptos tradicionales de vida, muerte y apreciación de nosotros mismos como seres humanos.

En otra mirada de este tema, Richard Lewinton plantea una visión futurista al relacionar conocimiento científico y democracia ${ }^{4}$. Sostiene que, en una sociedad dominada por la ciencia y la tecnología, el verdadero poder está en aquellos pocos que tienen este conocimiento y que para adoptar decisiones, la opinión de la mayoría pierde todo valor.

Hasta ahora, evidentemente es la sociedad quien ha influido en la ciencia de manera profunda, guiando o desvirtuando su investigación sea por razones económicas, políticas o ideológicas. Ejemplos de esto lo apreciamos todos los días y en la historia reciente: la legitimidad de la clonación reproductiva, los experimentos raciales en los campos de concentración, la limitación económica a la investigación pura o al apoyo de la formación de capital humano especializado ${ }^{5}$.

En salud, la Innovación (entendiendo por tal la aplicación de un conocimiento o una metodología) tiene un componente ético importante. Se abren una serie de preguntas ante la aplicación de una determinada técnica o de un procedimiento, que van más allá de la técnica misma y se dirigen más bien a las implicancias que tiene su aplicación.

¿Cuándo se hace indispensable un procedimiento? ¿De quién depende su aplicación? ¿A quiénes beneficia? ¿Cómo podría modificar nuestros conceptos de lo que es lícito o no?
¿Cuáles modificaciones en la docencia de los profesionales de la salud acarrea su uso? ¿Cuáles son los costos y beneficios económicos que significan para la "industria de la salud"?

En Medicina, hemos vivido una revolución especialmente en los campos de la genética y de la inmunología que han hecho posibles cosas impensadas hace pocos decenios: trasplantes de órganos, solución de problemas de fertilidad, mantención artificial de la vida. Junto a los aspectos positivos han surgido las infinitas pero también temibles posibilidades que estas mismas técnicas pueden eventualmente desarrollar, hasta llegar a la creación de vida, alterando lo que por siglos se ha considerado conceptos normales sobre la procreación y de las características de la especie. La discusión sobre el comercio genético ha llegado hasta el punto que Stewart Newman, distinguido biólogo celular, junto a un grupo connotado de personalidades, intentaron obtener una patente en la Oficina de Patentes norteamericana para treinta posibilidades que abarcan un espectro de quimeras animales-humanas, en busca de una "protección genética" que prohíba cualquier investigación con células embrionarias que atraviese las fronteras entre humanos y animales durante 20 años y permita en ese lapso una reflexión sobre el tema ${ }^{6}$.

Las expectativas del público respecto a la práctica médica y a la investigación clínica han cambiado en los últimos 30 años: hay un grado mayor de información, desgraciadamente no bien procesada (el llamado analfabetismo científico) $)^{7}$, que ha conducido, entre otras cosas, a una relación médico-paciente en un plano aparentemente igualitario, pero llevado a cabo en términos casi exclusivamente técnicos, lo que ha contribuido a deteriorar dicha relación en su valioso componente espiritual.

En relación a la investigación aplicada es necesario aclarar inquietudes que nos surgen como profesionales, por ejemplo:

¿Existen realmente las instancias efectivas de control ético en la investigación y la aplicación de los nuevos conocimientos? ¿Son los países en vías de desarrollo los más perjudicados con los estudios controlados de nuevos medicamentos? ${ }^{8}$.

En nuestro país se intenta contar con comi- 
tés éticos en instituciones universitarias y centros de salud, lo que se ha ido logrando con bastante dificultad por no existir tiempo protegido a los miembros institucionales para realizar esta delicada labor y porque su constitución no contempla, en la mayoría de los casos, una representación adecuada. Así la evidencia nos señala que aún gran parte de las líneas de investigación clínica no son sometidas a control cuando no acceden a fondos concursables, situación que afortunadamente se revierte en el ámbito de la investigación farmacológica.

La respuesta a las múltiples preguntas formuladas está en desarrollar una "ética de futuro" que se preocupe de las nuevas generaciones y de su sustentabilidad. La tarea es extremadamente difícil dado el carácter consumista y hedonista de la sociedad global. Sin embargo, la especie humana ha demostrado una capacidad de adaptación notable a través de los milenios y ha continuado desarrollándose a pesar de evidentes retrocesos y situaciones adversas. ¿Por qué negar la posibilidad de superar los problemas actuales?

La globalización tiene, entre otros, el efecto de ponernos en contacto diario con diversidad de opiniones, costumbres y valores. Esto debiera resultar en una mirada más amplia, sin embargo, esta misma diversidad hace también más difícil llegar a obtener un consenso sobre los valores mínimos para convivir en las sociedades pluralistas como destaca muy bien Adela Cortina en su Ética de mínimos y ética de máximos ${ }^{9}$.

Para llegar a constituirse en una sociedad pluralista sustentable el elemento educativo parece primordial: Pasa por asegurar la calidad de la enseñanza en todos los niveles, aprovechar en forma inteligente las herramientas tecnológicas, utilizar fuentes de información confiables, fomentar la tolerancia desde la más temprana edad y estimular el deseo de seguir incorporando conocimiento durante toda la vida.

Los elementos señalados son especialmente válidos en lo que se refiere a la enseñanza de la medicina: los médicos deben contar con un conjunto de valores y principios propios que aseguren un mínimo de justicia a sus acciones profesionales y respuestas acordes con la realidad que nos ha correspondido vivir. De ahí la importancia de la ética de las sociedades profesionales entendida como una reflexión filosófica de los valores morales, que se ajusten a los grandes principios aceptados universalmente, entre los que destaca la Declaración de los Derechos del Hombre.

\section{Referencias}

1.- Lolas F: Ética de la innovación tecnológica en Medicina. En: Ética e innovación tecnológica. Editorial Andros Impresores. Santiago, Chile 2006. págs 165-77.

2.- Norero $C$ : La proyección humanística en la enseñanza de la Medicina chilena del siglo XXI. Rev Chil Ped 2003; 74: 253-55.

3.- Norero $C$ : La humanización en Medicina. Discurso Inaugural. Ingreso a Medicina U. Andrés Bello, 2008. Viña del Mar. Boletín Hospital Viña del Mar 2008; 64: 76-80.

4.- Meade WT: Ethical and social issues arising from the science of Medicine. Balzan Symposium 2002. "Meeting the challenges of the future". Leo S. Olscki Editore 2003; págs 79-90.

5.- Norero C: Discurso Condecoración al Mérito Amanda Labarca 2003 Universidad de Chile. En: Huella y Presencia VI. Editora Amanda Fuller. Andros Impresores Santiago. Chile 2004; págs 97-102.

6.- Rifkin J: Biotecnología ¿Hacia un mundo feliz? En: Claves para el siglo XXI. Ediciones UNESCO 2000. págs 89-92.

7.- Krauskopf M: Riesgos del analfabetismo científico en la esfera pública. Ars Médica 2006; 13: 49-56.

8.- Salas $S$ : Aspectos éticos de la investigación biomédica: desafíos actuales de la investigación en países en vías de desarrollo. Ars Médica 2006; 13: 11-24.

9.- Cortina A: Pluralismo moral. Ética de mínimos y ética de máximos. Conferencia Facultad de Filosofía y Humanidades. Universidad de Chile. Mayo 2003. 